\title{
Health status of the Indian women- a brief report
}

\begin{abstract}
Healthy lifestyle and high intake of nutritious food can provide good health throughout life to the humans. The poor nutrition and unawareness on the utilization of health facilities during their childhood and reproductive age are the major factors responsible for the high maternal mortality. Though government of India has been taking several efforts to improve the health status of the women, poverty, gender discrimination and illiteracy in the population are the major problems associated with the implementation of appropriate interventions. The present overview focuses the major factors, which influence the health concerns of the women in India.
\end{abstract}

Keywords: malnutrition, maternal mortality, gender discrimination, women health, India
Volume 5 Issue 3 - 2017

\author{
Raju Kowsalya,' Shanmugam Manoharan² \\ 'Department of Biochemistry, Government Arts College for \\ Women, India \\ ${ }^{2}$ Department of Biochemistry and Biotechnology, Annamalai \\ University, India
}

\begin{abstract}
Correspondence: Manoharan, Associate Professor, Department of Biochemistry and Biotechnology, Faculty of Science, Annamalai University, Annamalainagar, Tamil Nadu, 608002, India, Tel +9|4|44 239|4I, Fax +9|4|44238080, Email sakshiman@rediffmail.com
\end{abstract}

Received: February 13, 2017 | Published: April 06, 2017

\section{Introduction}

Women's health concern is influenced by interrelated biological, social, and cultural factors (Figure 1). It is generally expected that women can live longer than men it does not necessarily ensure a better quality of life. Profound studies reported that women are more sickly and disabled than men throughout the life cycle. It has been suggested that women are particularly vulnerable, where basic maternity care is unavailable. ${ }^{1}$ Due to the involvement of biological factors, women are more prone to sexual exposure of contracting sexually transmitted infections (STIs), including the human immunodeficiency virus
(HIV) than do men. ${ }^{2}$ Moreover an early marriage and childbirth could be responsible for the prevailing wide variation in the socioeconomic status. Profound studies pointed out the voluntary involvement of the community, paramedical workers, NGO, policy makers and teachers in various developmental programs for the removal of poverty and improve the literacy rate among females. ${ }^{3}$ Nutrition and health education should be strengthened via department of health to improve the nutritional status of mother and child, which are intimately linked. ${ }^{4}$ A strong and sustained government commitment is therefore needed to improve women's, health concern. ${ }^{5}$

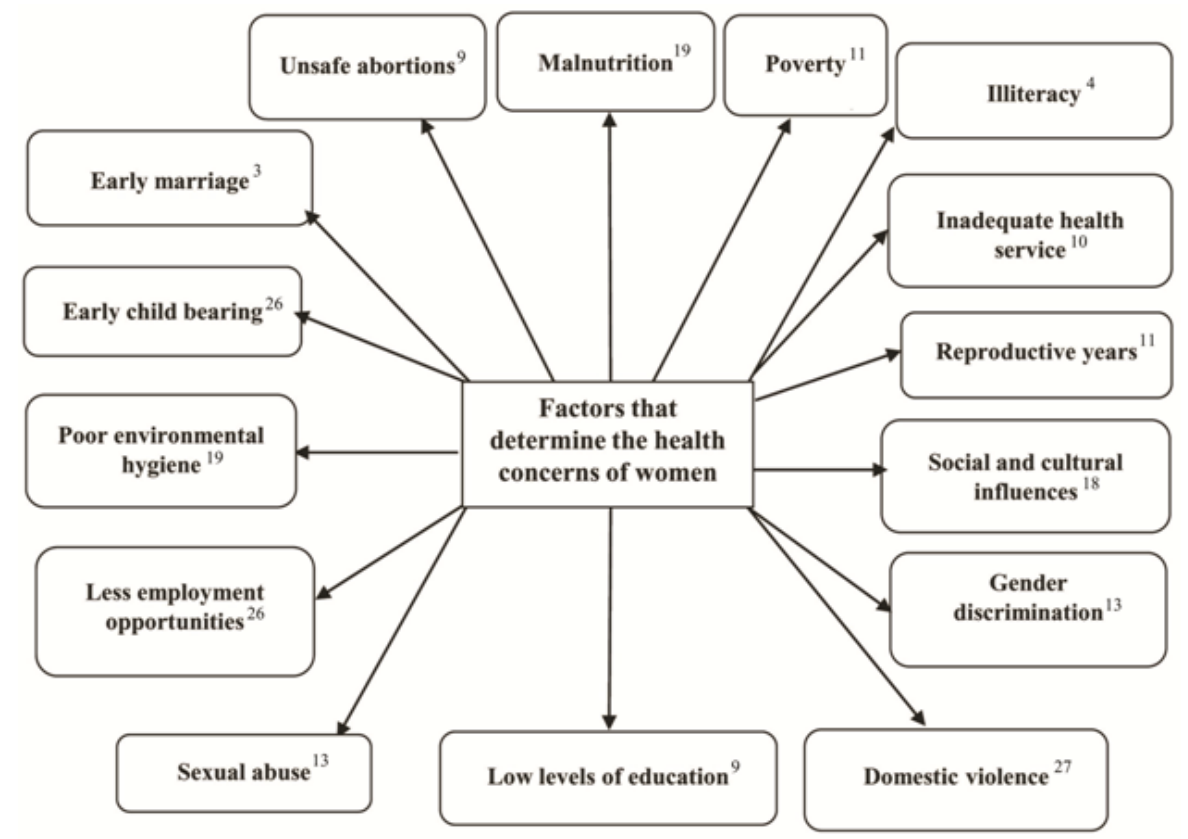

Figure I Factors that determine the health concerns of the women.

\section{Health and nutritional status of Indian women}

It has been suggested that the health and nutritional status of Indian women becoming worse due to the prevailing culture and traditional practices in India. Indian women are generally vulnerable to poor nutrition, especially during pregnancy and lactation. It has been pointed out that the impact of nutritional status of the mother is more pervasive than the impact of other factors on birth weight. ${ }^{6}$ It has been observed that the dietary intake of rural pregnant women was lower than the recommended level. ${ }^{7}$ Usually low weight infants are 
born to mothers with under nutrition and poor health. The incidence of anaemia was found to be highest among lactating women followed by pregnant women and adolescent girls. Epidemiological studies pointed out that worldwide 50 percent of all pregnant women are anaemic, and at least 120million women in less developed countries are underweight. ${ }^{8}$ In South Asia, an estimated 60 percent of women are underweight. Pregnant adolescents, especially who are underweight, are at greater risk of various complications such as obstructed labour and other obstetric complication. ${ }^{9}$ Unawareness on health care during pregnancy thus results in negative outcomes for both the mother and the child. ${ }^{10}$ Right and proper education to the mothers had a significant influence on their nutritional status and their health. The definitive steps should be taken to educate women about the importance of health care for ensuring health pregnancies and safe childbirths.

\section{Gender discrimination}

Women's disproportionate poverty, low socioeconomic status, gender discrimination and reproductive role not only expose them to various diseases, but also their accesses to and use of health services. ${ }^{11}$ Domestic violence, rape, and sexual abuse against women affect their productivity, autonomy, quality of life, and physical and mental well being. A surprising report pointed out that women who lost male partner are often forced into prostitution to lead their life. Men transmit the infectious virus to women fourfold than women are to men. Women also acquire HIV infection when they receive blood transfusions to combat pregnancy-related anaemia or hemorrhage. ${ }^{12}$ Sexual abuse during childhood enhances the mental depression and reproductive tract infections in later life, which could often lead to female infertility. Gender discrimination (son preference) along with high dowry costs for their daughters, marriage, often results in the mistreatment of daughters. Bias in both education and formal labor force participation as well as leading the life under the control of their fathers, husbands, and sons could exert a negative impact on the health concerns of Indian women. Though worldwide women have increased life expectancy at birth, the systemic problems associated with Indian women's health chances of a typical female advantage. ${ }^{14}$ In India, both men and women have the same life expectancy at birth. Financial support, old age security, property inheritance and dowry all contribute to the preference of sons over daughters. The Indian government has, however taken necessary steps to alleviate the current gender discrimination. Unwanted and illegal pregnancies terminated by unsafe abortions could have negative consequences for women's health. Reducing fertility may often improve the overall health of Indian women. ${ }^{15}$ The torture and violence given to women by her husband and mother-in-law could also be a key faster for the negative impact on the health and mental status of the Indian women. Children who born to mothers with low level of education suffer from nutritional disorders twice fold than mothers with higher education. ${ }^{16}$

\section{Malnutrition}

Malnutrition, due to deficiencies of calories, protein, vitamins, and minerals and other poor health and social status, affects millions of women and adolescent girls around the world (Figure 2). Malnutrition, a serious health concern, threatens the survival of Indian mothers and their children. Adequate nutrition is thus an essential cornerstone to maintain the healthy health of any individual, especially for women. ${ }^{17}$ Baby born to malnourished women faces multiple complications, including cognitive impairments, short stature, lower resistance to infections, and a higher risk of disease and death throughout their lives. Women are more prone to nutritional deficiencies than men due to the fact of women's reproductive biology, low social status, poverty, and lack of education. ${ }^{18}$ The two most common nutritional deficiencies in the women worldwide are iron deficiency and anaemia. Around $80 \%$ of the Indian pregnant women suffer from iron deficiency anaemia's. ${ }^{8}$ Nutritional deficiencies, including iron and iodine deficiencies and low intake of essential nutrients could enhance the chances of having a low birth-weight infant, as well as impaired fetal development in pregnant women. Low intake of nutrition during girls' childhood may cause stunted growth, which in turn leads to higher risks of complications during and following childbirth. ${ }^{6}$ Mental impairments impede physical development, and harm school performance is the common consequences of iodine deficiency among adolescent girls. Maternal malnutrition often results due to the kind of reproductive cycle, they have and spending more times on household work. Around 450million women are underweight due to protein energy malnutrition during their childhood in developing countries. The highest incidence of malnutrition among women is reported in South Asia. ${ }^{19}$ The disorders associated with malnutrition in women ${ }^{6,20-27}$ is presented in Figure 2.

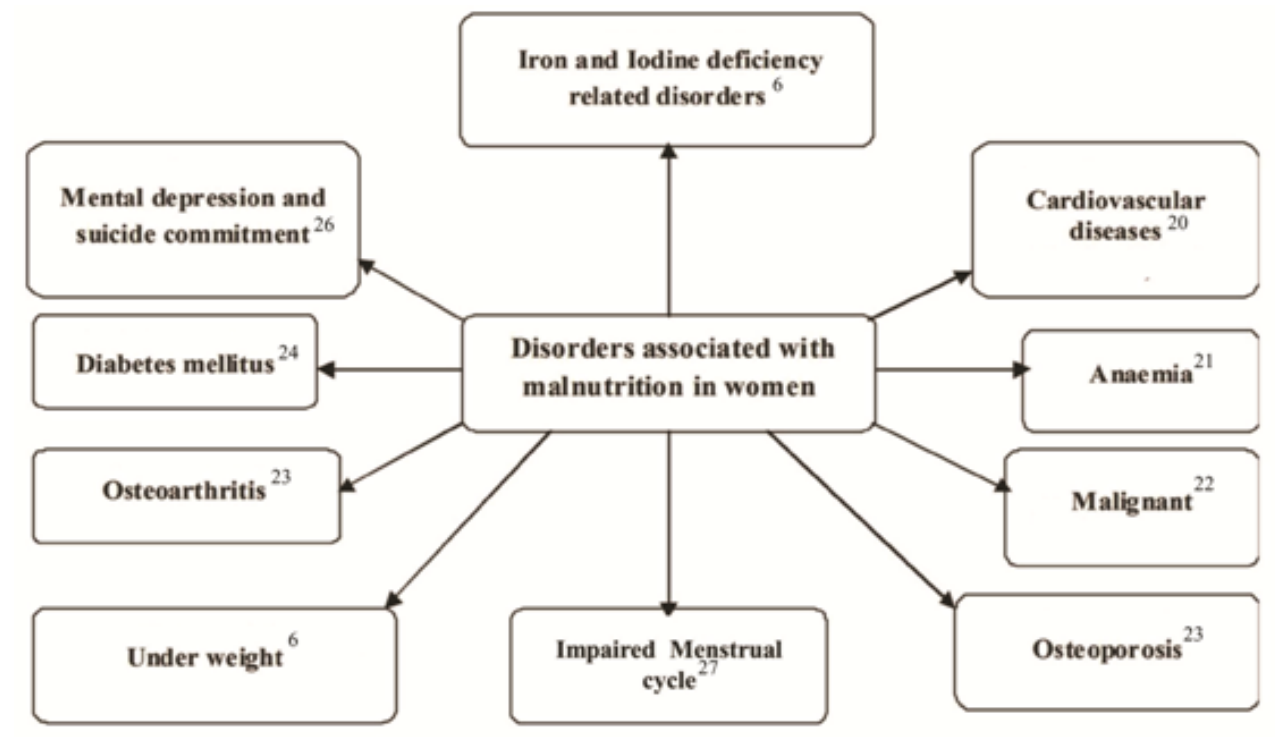

Figure 2 Disorders associated with malnutrition in women. 


\section{Maternal mortality}

Maternal mortality remains stubbornly high in India as compared to many developing nations India contributed approximately 20 percent of all maternal deaths worldwide between 1992 and 2006; due to lower socioeconomic status and cultural constraints as well as limiting access to health care. ${ }^{6}$ Maternal mortality is 57 fold higher in Indian women than in the United States. India's maternal mortality ratio is lower than the ratios for Bangladesh and Nepal, while it is higher than those in Pakistan and Sri Lanka. ${ }^{25}$ Severe anemia accounts for $20 \%$ of all maternal deaths in India. It has been suggested that, higher literacy has greater maternal health as well as lower infant mortality. Cardiovascular disease is the major contributor to increased female mortality in India, which is due to differential access to health care between the sexes..$^{20}$ Surprisingly men are tend to visit hospitals more frequently than women to treat their ill-health. Moreover, Indian women suffer from mental depression at higher rates than Indian men.26 More Indian women committed suicide as compared to men, which are directly related to depression, anxiety, gender disadvantage and anguish related to domestic violence. Very strict, strong and sustained laws should be framed by the government to prevent the gender based violence in as well as to improve the educational and health status of the women. ${ }^{27}$

\section{Conclusion}

Good health is a key criterion, which contributes to human wellbeing and economic growth. Adequate nutrition for women would help them to serve as productive members of the society to develop the consequent health generations. The government should take necessary and compulsory policies to improve the literacy rate and quality education as well as to provide adequate employment opportunities for women, which might explore positive impact on the women's health concerns. The government can also improve the health status of women by strengthening and expanding essential health services as well as by frequent counselling on safe sex, awareness on educational and nutritional needs and gender based violence.

\section{Acknowledgements}

None.

\section{Conflict of interest}

The author declares no conflict of interest.

\section{References}

1. Ginter E, Simko V. Women live longer than men. Bratisl Lek Listy. 2013; $114: 45-49$

2. Ramjee G, Daniels B. Women and HIV in Sub-Saharan Africa. AIDS Res Ther. 2013;10:30.

3. Onarheim KH, Iversen JH, Bloom DE. Economic Benefits of Investing in Women's Health: A Systematic Review. PLoS One. 2016;11(3):e0150120.

4. Branca F, Piwoz E, Schultink W, et al. Nutrition and health in women, children, and adolescent girls. BMJ. 2015;51:h4173.

5. Davidson PM, McGrath SJ, Meleis AI, et al. The health of women and girls determines the health and well-being of our modern world:A white paper from the International Council on Women's Health Issues. Health Care Women Int. 2011;32(10):870-886.

6. Dharmalingam A, Navanethan K, Krishnakumar CS. Nutritional status of mothers and low birth weight in India. Matern Child Health $J$. 2010;14(2):290.

7. Durrani AM, Rani A. Effect of maternal dietary intake on the weight of the newborn in Aligarh city, India. Niger Med J. 2011;52:177-181.
8. Mallikharjuna Rao K, Balakrishna N, Arlappa N, et al. Diet and Nutritional Status of Women in India. J Hum ecol. 2010;29(3):165-170.

9. Ghosh-Jerath S, Devasenapathy N, Singh A, et al. Ante natal care (ANC) utilization, dietary practices and nutritional outcomes in pregnant and recently delivered women in urban slums of Delhi, India: An exploratory cross-sectional study. Reprod Health. 2015;12:20.

10. Yazdkhasti M, Pourreza A, Pirak A, et al. Unintended Pregnancy and Its Adverse Social and Economic Consequences on Health System:A Narrative Review Article. Iran J Public Health. 2015;44(1):12-21.

11. Sanneving L, Trygg N, Saxena D, et al. Inequity in India: the case of maternal and reproductive health. Glob Health Action. 2013;6:19145.

12. Schantz-Dunn JMN. The Use of Blood in Obstetrics and Gynecology in the Developing World. Rev Obstet Gynecol. 2011;4(2):86-91.

13. Condorelli R. An emergentist vs a linear approach to social change processes: a gender look in contemporary India between modernity and Hindu tradition. Springer Plus. 2015;4:156.

14. Namasivayam A, Osuorah DC, Syed R, et al. The role of gender inequities in women's access to reproductive health care: a populationlevel study of Namibia, Kenya, Nepal, and India. Int $J$ Womens Health. 2012;4:351-364.

15. Omar SS. Gender Discrimination: Its Unhealthy Demographic Outcome and Measures of Intervention. Asian Journal of Research in Social Sciences and Humanities. 2015;5:62-66.

16. Khadilkar VV, Mandlik RM, Palande SA, et al. Growth status of small for gestational age Indian children from two socioeconomic strata. Indian J Endocr Metab. 2016;20(4):531-535.

17. Paul VK, Sachdev HS, Mavalankar D, et al. Reproductive health, and child health and nutrition in India: meeting the challenge. Lancet. 2011;377(9762):332-349.

18. Anita R, McDougal LP, Silverman JG. Gendered effects of siblings on child malnutrition in South Asia: Cross-sectional analysis of demographic and health surveys from Bangladesh, India, and Nepal. Matern Child Health J. 2015;19(1):217.

19. Tzioumis E, Adair LS. Childhood dual burden of under- and overnutrition in low- and middle-income countries: a critical review. Food Nutr Bull. 2014;35(2):230-243.

20. Krishnan MN. Coronary heart disease and risk factors in India - On the brink of an epidemic? Indian Heart J. 2012;64(4):364-367.

21. Girija PL. Anaemia among women and children of India. Anc Sci Life. 2008;28(1):33-36.

22. Gadomska H, Grzechocia B, Janecki J, et al. Serum lipids concentration in women with benign and malignant ovarian tumours. Eur J Obstet Gynecol Reprod Biol. 2005;120(1):87-90.

23. Pecina JL, Romanovsky L, Merry SP, et al. Comparison of clinical risk tools for predicting osteoporosis in women ages 50-64. J Am Board Fam Med. 2016;29(2):233-239.

24. Massé PG, Pacifique MB, Tranchant CC, et al. Bone metabolic abnormalities associated with well-controlled type 1 diabetes (IDDM) in young adult women: a disease complication often ignored or neglected. $J$ Am Coll Nutr. 2010;29(4):419-429.

25. World Health Organisation (WHO). Global Strategy for infant and young child feeding. Geneva: World Health Organisation; 2003.

26. Bohra N, Srivastava S, Bhatia MS. Depression in women in Indian context. Indian J Psychiatry. 2015;57(6):S239-S245.

27. Halder A, Vijayselvi R, Jose R. Changing perspectives of infectious causes of maternal mortality. J Turk Ger Gynecol Assoc. 2015;16(4):208213. 